\title{
Present-day and future mediterranean precipitation extremes assessed by different statistical approaches
}

\author{
A. Paxian $\cdot$ E. Hertig $\cdot$ S. Seubert $\cdot$ G. Vogt $\cdot$ \\ J. Jacobeit $\cdot$ H. Paeth
}

\begin{abstract}
The Mediterranean area is strongly vulnerable to future changes in temperature and precipitation, particularly concerning extreme events, and has been identified as a climate change hot spot. This study performs a comprehensive investigation of present-day and future Mediterranean precipitation extremes based on station data, gridded observations and simulations of the regional climate model (REMO) driven by the coupled global general circulation model ECHAM5/MPI-OM. Extreme value estimates from different statistical methods-quantile-based indices, generalized pareto distribution (GPD) based return values and data from a weather generator-are compared and evaluated. Dynamical downscaling reveals improved small-scale topographic structures and more realistic higher rainfall totals and extremes over mountain ranges and in summer. REMO tends to overestimate gridded observational data in winter but is closer to local station information. The dynamical-statistical weather generator provides virtual station rainfall from gridded REMO data that overcomes typical discrepancies between area-averaged model rainfall and local station information, e.g. overestimated numbers of rainy days and underestimated extreme intensities. Concerning future rainfall amount, strong summer and winter drying over the northern and southern Mediterranean, respectively, is confronted with winter wetting over the northern part. In contrast, precipitation extremes tend to increase in even more Mediterranean areas, implying
\end{abstract}

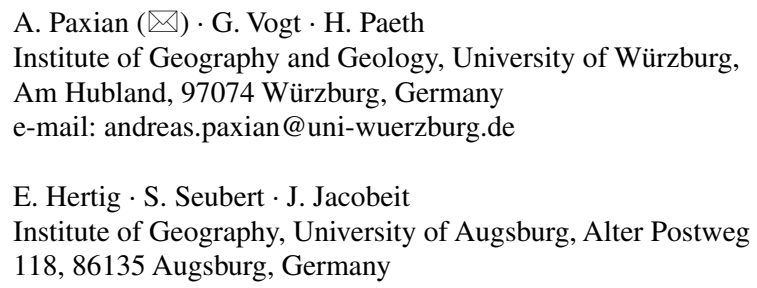

regions with decreasing totals but intensifying extremes, e.g. southern Europe and Turkey in winter and the Balkans in summer. The GPD based return values reveal slightly larger regions of increasing rainfall extremes than quantilebased indices, and the virtual stations from the weather generator show even stronger increases.

Keywords Mediterranean climate $\cdot$ Precipitation extremes · Quantiles · GPD · Weather generator · Regional climate modelling

\section{Introduction}

In the recent decades, various weather and climate extremes exerted a severe impact on society, economy and ecology in the Mediterranean area. One of the most striking examples was the prolonged European heat wave in summer 2003 with record-breaking temperatures (García-Herrera et al. 2010) and extended forest fires throughout the western Mediterranean area (Trigo et al. 2006). It was identified as the hottest summer since at least 500 years (Luterbacher et al. 2004). Further prominent extreme events were given by an extra-tropical cyclone causing persistent extreme rainfall, extended flooding and landslides over the Po valley in October 2000 (Turato et al. 2004) and the strongest drought of the last 140 years over Iberia from October 2004 to September 2005 with intensively decreased rainfall and agricultural and hydroelectricity production (GarcíaHerrera et al. 2007). The exposure and sensitivity of the Mediterranean area to such extreme events is supposed to increase in the light of the recently observed prominent warming and drying over the whole area. At the same time, the Mediterranean region is characterized by a relatively low capacity for adaptation due to dense population 
and scarce and partly over-exploited natural resources like freshwater and land (Plan Bleu 2005; Lionello et al. 2006; Hoff 2008; Plan Bleu and European Investment Bank (EIB) 2008). Therefore, robust estimates of the frequency and intensity of extreme events and their changes in a warmer climate are highly relevant to political decision-makers in Mediterranean countries in order to implement adequate measures of future mitigation and adaptation (Changnon 2003).

Observations often reveal large seasonal trends of rainfall and temperature over the Mediterranean region. During the second half of the twentieth century, the prevailing winter rainfall tendency is negative but without clear spatial coherence and mostly not significant (Xoplaki 2002). In the last decades of the twentieth century, an area-wide decrease of winter and spring precipitation is observed in the western areas (Jacobeit 2000; Goodess and Jones 2002; García et al. 2007; Del Río et al. 2010) with some positive trends over the south-eastern part (Jacobeit et al. 2007). Concerning temperature, a significant warming occurred in the western half and a slight cooling over the eastern part since about 1950 (Jacobeit 2000; Xoplaki 2002). More recently, warming trends prevail everywhere (Miranda and Tomé 2009), especially in summer (Toreti 2010). Overall, winters during recent decades were found to be the driest and warmest since 500 years (Luterbacher et al. 2004; Pauling et al. 2006).

Concerning observed trends of extreme events, increasing frequencies and persistence of Mediterranean dry periods or droughts are consistent with decreasing rainfall during the late twentieth century (Xoplaki et al. 2004; García-Herrera et al. 2007). In contrast, recent trends of heavy rainfall are often controversial between different studies, methods and regions and less consistent with present-day drying: over the Iberian Peninsula, Alpert (2002) identified increases of heavy rainfall exceeding $64 \mathrm{~mm} /$ day, but Rodrigo (2010) and López-Moreno et al. (2010) found negative or not significant trends in the occurrence of rainfall extremes exceeding the 95th and 90th percentiles, respectively. Over Italy, Alpert (2002) and Kostopoulou and Jones (2005) revealed increasing frequencies of torrential (>128 mm/day) and intense rainfall events, respectively. Over the Balkans and Turkey, Kostopoulou and Jones (2005) found decreasing occurrences of intense rainfall events, but Norrant and Douguédroit (2006) pointed to increasing heavy rainfall over Greece. Furthermore, Toreti et al. (2010) identified no significant changes or decreases in the occurrence of winter rainfall extremes by fitting generalized pareto distribution (GPD) functions, confirmed by Kioutsioukis et al. (2010) for return values (RVs) of the GPD and generalized extreme value (GEV) distribution over Greece. In terms of temperature extremes, observed changes are consistent with trends of mean temperature and tend towards warmer extreme indices for daily minimum and maximum temperatures, especially in summer (Klein Tank and Können 2003; Kostopoulou and Jones 2005; Moberg et al. 2006; Hertig et al. 2010; Efthymiadis et al. 2011). RVs from GPD and GEV distributions suggest warmer minimum and maximum temperatures over Greece (Kioutsioukis et al. 2010), and increasing intensities of summer heat waves were found over the whole area (DellaMarta et al. 2007; Kuglitsch et al. 2010).

With respect to climate model simulations, Giorgi and Lionello (2008) reviewed the global coupled atmosphereocean general circulation model (GCM) simulations of the fourth Assessment Report (AR4) of the Intergovernmental Panel on Climate Change (IPCC) for the Mediterranean area and pointed to a generally good agreement of present-day temperature and rainfall means with gridded observations. However, orographic effects are not well represented in the coarse resolution of GCMs $(120-450 \mathrm{~km})$, resulting in noticeable warm and dry biases in mountainous regions (Giorgi and Coppola 2009). They concluded that the complex orographic and land-sea contrasts of the Mediterranean area require the use of high-resolution regional climate models (RCMs, $\sim 50 \mathrm{~km}$ grid) which are able to simulate such small-scale topographic details. Indeed, Jacob et al. (2007) found mostly smaller biases to observations in ten RCMs than in the driving GCM HadAM3H in winter but less improvement of GCM biases in summer. Giorgi and Coppola (2009) revealed smaller summer rainfall biases in an RCM ensemble than in the driving GCM ensemble. Further added values of dynamical downscaling were found in terms of surface winds over orography (Sotillo et al. 2005), rainfall extremes (Deque and Somot 2008) and river discharge (Sanchez-Gomez et al. 2009).

Concerning the future perspective of Mediterranean climate, Giorgi and Lionello (2008) showed a strong agreement of 17 global GCM simulations in the form of a large warming and drying under the $\mathrm{A} 1 \mathrm{~B}$ emissions scenario until 2100: warming peaks over Spain and the Balkans in summer. Rainfall reduction reaches $-40 \%$ over the northern areas in summer and $-30 \%$ over the southern part in winter (but small increases occur over the northern areas in winter). The $\mathrm{A} 2$ and $\mathrm{B} 1$ scenarios reveal larger and smaller warming and drying, respectively. These GCM projections are basically confirmed by RCM experiments in the framework of the PRUDENCE (Christensen and Christensen 2007; Giorgi and Coppola 2009) and ENSEMBLES projects (Goodess et al. 2009), but with more detailed spatial trend patterns (Giorgi and Lionello 2008; Giorgi and Coppola 2009). However, Boberg and Christensen (2012) revealed that both GCMs and RCMs tend to overestimate future Mediterranean summer warming by $10-20 \%$ due to systematic temperature-dependent biases. Overall, Giorgi (2006) identified the Mediterranean area as a primary 
climate change hot spot, i.e. one of the most responsive regions to changes in radiative forcing, with large agreement among climate models and standing out from internal climate variability. Nonetheless, shorter-term climate trends are not necessarily in phase between models and observations due to the unknown initial conditions of model experiments (Paxian et al. 2013).

In terms of future changes in extreme events, GCM and RCM projections widely agree in simulating increasing risks of dry spells and droughts (Voss et al. 2002; Tebaldi et al. 2006; Beniston et al. 2007), consistent with recently observed changes. In contrast, an incoherent picture is drawn for heavy rainfall: Semmler and Jacob (2004) stated increasing GEV RVs over the central part. Goubanova and $\mathrm{Li}$ (2007) found the same tendency over the northern part in winter but slight decreases or no changes in summer. Gao et al. (2006) confirmed the latter results, in contrast to Christensen and Christensen (2003) denoting increasing intensities of heavy summer rainfall episodes over the western Mediterranean area. Paeth and Hense (2005) also pointed to decreasing winter and increasing summer GPD RVs over the western and eastern parts, respectively. While Beniston et al. (2007) suggested less intense heavy winter and summer rainfall over southern Europe, Pal et al. (2004) and Gao et al. (2006) found increasing frequencies of both Mediterranean droughts and floods at least in summer. Frei et al. (2006) highlighted the large inter-model differences in trends of summer extremes over southern Europe. Concerning recent Coupled Model Intercomparison Project Phase 5 (CMIP5) GCM simulations, Kharin et al. (2013) found increasing 20-year GEV RVs (associated with decreasing return periods) for annual extremes of daily rainfall over the northern Mediterranean. This is confirmed by Toreti et al. (2013) for 50-year GPD RVs in winter, but hardly any model consistency or reliability is found in summer or over the southern parts. However, higher model agreement prevails with respect to warmer daily minimum and maximum temperatures (Diffenbaugh et al. 2007; Kjellström et al. 2007) and stronger heat waves (Meehl and Tebaldi 2004; Beniston et al. 2007; Fischer and Schär 2010).

Generally, the statistical assessment of extreme events is subject to uncertainty because the sample size of rare events is small by definition (Palmer and Räisänen 2002; Hertig et al. 2012a). This affects the estimate of distinct percentiles and parameters of extreme value distributions from given model and observational data sets. Paeth and Hense (2005) highlighted the need for large sample sizes, however, for small rainfall samples over the dry Mediterranean area they successfully applied the method of L-moments to estimate GPD parameters and a Monte Carlo sampling approach to evaluate RV uncertainties with regard to sampling errors (cf. Hosking 1990; Kharin and Zwiers 2000). Concerning observational data, further uncertainty arises from low spatial or temporal coverage and inhomogeneities (Della-Marta and Wanner 2006). On the basis of climate model data and gridded observations, other deficiencies occur, i.e. an overestimated number of low-intensity rainfall events and underestimated extreme rainfall intensities compared to station data (Zolina et al. 2004). This drawback can be partly overcome by a dynamical-statistical weather generator (WG) which produces virtual station time series of daily precipitation from gridded climate model data applying physical and statistical adjustments to local stations (Paeth and Diederich 2010).

In the light of these uncertainties, the main objective of the present study is a systematic assessment of present-day and future Mediterranean precipitation extremes based on different data sets, various estimates of extreme events and a thorough consideration of uncertainty. The analysis relies on GCM and RCM simulations, gridded and station-based observations and the virtual station data from a dynamicalstatistical WG. Two statistical methods of extreme value analysis are used, i.e. quantile-based extreme indices and fitting of a theoretical distribution-in this case the GPD (Coles 2001). Thereby, we try to shed some light on the inconsistencies between previous works on Mediterranean rainfall extremes which were based on different data sets and extreme value statistics. In addition, the potential added value of dynamical downscaling from global to regional scale is assessed in this region where small-scale orographic and land-see contrasts are that pronounced. The following section is dedicated to the considered model and observational data. Extreme value statistics and the WG are described in Sect. 3. Section 4 deals with the corresponding results which are discussed in Sect. 5.

\section{Data}

For the validation of simulated precipitation totals and extremes, the land-only daily observational E-OBS data set of the ENSEMBLES project covering whole Europe and parts of northern Africa on a $0.5^{\circ}$ grid for the period 1950-2008 is used (Haylock et al. 2008). In the light of data gaps, only those E-OBS grid boxes are considered for further analysis which fulfil the following standards (cf. Moberg and Jones 2005): a complete month contains a maximum of two missing days, a complete season contains no missing months, and a complete time series no missing seasons in the given time period. Hence, several grid boxes over northern Africa, the Near East and Turkey are not taken into account.

For the WG, the following input data sets were collected: 330 daily precipitation station records in the Mediterranean area have been derived from the GLOWA JR Project (Global Change and the Hydrological Cycle Jordan River, 
Kunstmann et al. 2006), the EMULATE project (European and North Atlantic daily to MULtidecadal climATE variability, Moberg et al. 2006), the ECA\&D project (European Climate Assessment \& Dataset, Klein Tank et al. 2002), and the MedCLIVAR programme (Mediterranean CLImate VARiability and Predictability). After applying homogeneity tests following Wijngaard et al. (2003) and the data completeness standard mentioned above 93 precipitation stations remain for subsequent analyses. Highest station density prevails over the Iberian Peninsula and the Near East, several stations are available over the central Mediterranean area, but only two stations are found over entire northern Africa (cf. Fig 4, top right). In addition, we use $10 \mathrm{~m}$ zonal and meridional daily wind fields at $2.5^{\circ}$ horizontal resolution from the global ERA40 reanalysis data (Uppala et al. 2005) of the European Centre for MediumRange Weather Forecasts (ECMWF) over the period 19572002. Finally, we use the Shuttle Radar Topography Mission (SRTM) Finished Grade raster elevation data from the United States Geological Survey (USGS) at $90 \mathrm{~m}$ resolution (Farr et al. 2007).

In terms of dynamical downscaling, the hydrostatic RCM REMO is used (Jacob 2001; Jacob et al. 2001, 2007). The model domain is centred over Africa and extends from $30^{\circ} \mathrm{W}$ to $60^{\circ} \mathrm{E}$ and from $15^{\circ} \mathrm{S}$ to $45^{\circ} \mathrm{N}$ with a horizontal resolution of $0.5^{\circ}$ and 20 hybrid vertical levels up to $25 \mathrm{~km}$ height (Paeth et al. 2005). We investigate the Mediterranean sector extending from $20^{\circ} \mathrm{W}$ to $45^{\circ} \mathrm{E}$ and from $25^{\circ} \mathrm{N}$ to $44^{\circ} \mathrm{N}$. Two grid point rows $\left(1^{\circ}\right)$ have been removed from the northern rim to avoid lateral boundary effects like artificial rainfall. The REMO experiments are nested into simulations of the global coupled atmosphere-ocean GCM ECHAM5/MPI-OM (Roeckner et al. 2003; Jungclaus et al. 2006) at T63 $\left(\sim 1.875^{\circ}\right)$ resolution, covering the period 1960-2050. During 1960-2000 observed GHG concentrations are considered, afterwards the emissions scenarios A1B and B1 are prescribed (Nakicenovic and Swart 2000). In addition, a scenario of man-made land-cover changes is implemented, especially over sub-Saharan Africa but not in the European part of the Mediterranean region (Paeth et al. 2009). For the twentieth-century and both future scenarios, we analyse the ensemble mean of three ensemble members each.

\section{Methods}

For the analysis of Mediterranean rainfall totals and extremes, we choose 1961-1990 and 2021-2050 as present-day and future reference periods, respectively, and refer to winter (DJF) and summer (JJA) seasons. Linear trends of rainfall totals during 1961-2050 are tested by means of a two-tailed $t$ test at a significance level of $5 \%$
(Wilks 2006). The preconditions of linear regression, i.e. normal distribution of data and independence of residuals, have successfully been proved via Kolmogorov-Smirnov tests and autocorrelation functions, respectively (Wilks 2006), except for some regions in northern Africa and the Arabian Peninsula where summer rainfall does not follow a normal distribution (though, the more crucial independence assumption is not violated). However, we are aware that a linear model might hide more complex time dependent components of the analysed time series, e.g. change points.

Extreme precipitation events are once determined based on empirical quantiles (Moberg et al. 2006) and once relying on a theoretical distribution (Coles 2001; Smith 2003; Wilks 2006). The first method determines the $\mathrm{q}(\%)$ quantile $M_{q}$ of an ordered data sample $x_{1} \leq x_{2} \leq \cdots \leq x_{n}$ of size $\mathrm{n}$ following an empirical approach from Moberg et al. (2006) with $\mathrm{k}$ rounded down from $k=n q / 100$ :

$M_{q}=\frac{(100-q) x_{k}+q x_{k+1}}{100}$

In this study, the moderately extreme $95 \%$ quantile is considered for the investigation of daily precipitation sums because it allows for a larger sample size compared to higher percentiles and, hence, more accurate statistics (Hertig et al. 2012a), especially during the dry Mediterranean summers. Two seasonal quantile-based precipitation extreme indices are chosen to investigate both frequency and intensity of precipitation extremes: the number of days [R95N (days)] and the mean daily rainfall amount of days exceeding the 95th quantile threshold [simple daily intensity index SDII95p (mm)], counting only rainy days with sums larger than $0.1 \mathrm{~mm}$ (Moberg et al. 2006; Hertig et al. 2012a). For both present-day and future extremes, the $95 \%$ quantile is derived from the present-day reference period 1961-1990. In order to avoid artificial breaks in the quantile-based extreme index time series of the present-day reference period (which might occur when using the same data for estimating the $95 \%$ quantile and the threshold exceedances), a bootstrapping approach is applied leaving out the particular year for which threshold exceedances are counted while determining the $95 \%$ quantile threshold from the remaining years (cf. Zhang et al. 2005). Counting threshold exceedances of the future reference period is carried out without this bootstrap technique. The seasonal quantile-based extreme index time series are averaged over 1961-1990 and 2021-2050 and future changes are calculated for both emissions scenarios. The significance of future change is assessed by a two-tailed sample mean $t$ test at an error level of $5 \%$. We are aware that, typically, precipitation extremes are not normally distributed, yet the $t$ test is not very sensitive towards the violation of this precondition (Von Storch and Zwiers 1999). 
The second method defines extreme precipitation on the basis of RVs derived from a theoretical distribution. In contrast to quantiles, this approach reduces sampling errors (Schönwiese 2006) and allows for the extrapolation towards return periods outside the sample period, however, with clearly increased domains of uncertainty. A drawback is that the parameters of the distribution have to be estimated from typically small samples (Hosking 1990). In this case, we fit the GPD to daily extremes exceeding a certain threshold. This peaks-over-threshold approach relies on more data and is more appropriate for daily time series than e.g. the GEV distribution which considers block maxima (Coles 2001; Smith 2003; Wilks 2006). Again, only rainy days with precipitation amounts higher than $0.1 \mathrm{~mm}$ are taken into account. The GPD can be described by three parameters, namely the location $\zeta$, scale $\alpha$ and shape $\mathrm{k}$ (Paeth and Hense 2005). However, the location parameter can also be implicitly incorporated into the scale parameter (Coles 2001). We estimate the GPD parameters from the sample of observed or simulated precipitation extremes (exceeding a certain threshold which is defined further below) for the present-day or future reference period applying the method of L-moments which is relatively robust in the light of potential outliers and small rainfall samples over the dry Mediterranean area (Hosking 1990; Paeth and Hense 2005). Then, the RVs of daily extremes at various return times (RTs) are determined as (1-1/RT) quantiles of the cumulative GPD function taking into account the probability of occurrence, i.e. the probability of being above the threshold.

The uncertainty of the RV estimates with regard to sampling errors is assessed by means of a parametric bootstrap sampling approach which is especially appropriate for the particularly large and influential sampling errors of small Mediterranean rainfall samples during summer and over the southern regions (Kharin and Zwiers 2000; Paeth and Hense 2005; Wilks 2006): new random samples of equal size are drawn from GP distribution with parameters estimated by using the original data sample. Then, for each random sample the GPD parameters are again inferred and the RVs derived. Thus, RV means and standard deviations (which define the corresponding RV standard errors) are computed over all random samples. RVs can be assumed to be normally distributed over random samples (Park et al. 2001). Finally, the overlapping of RV confidence intervals based on these standard errors is taken as a measure of statistical significance of extreme precipitation changes between the present-day and future reference periods (Kharin and Zwiers 2000; Paeth and Hense 2005). Generally, the choice of the GPD threshold is difficult enhancing either variance or bias: if chosen too high, the smaller data sample exceeding the threshold causes large variance in the estimation of GPD parameters, particularly the shape parameter. If chosen too low, the distribution of threshold exceedances might be not in the domain of attraction of the applied extreme value distribution GPD inducing large bias (Coles 2001; Smith 2003). However, Paeth and Hense (2005) found a higher sensitivity of GPD parameters and resulting RVs to bootstrap samples (and thus, sampling errors) than to quantile thresholds from 85 to $95 \%$ for daily rainfall extremes of several seasons and subregions of the Mediterranean Basin. Additionally, performing further sensitivity tests with our data samples we did not reveal any clear physical pattern in the quantile threshold choice carried out by Paeth and Hense (2005), i.e. selecting those quantile thresholds from 85 to $95 \%$ with minimum RV standard error, over different variables, seasons or Mediterranean regions.

In order to account for both uncertainties, our final RVs and standard errors (for estimating RV confidence intervals) to be analysed represent the mean and standard deviation over 100 random samples and 11 quantile thresholds ranging between $\mathrm{q}=85$ and $\mathrm{q}=95 \%$. RTs are chosen to be $5,10,15,20,25$ and 30 years, but only 20 -year RVs are shown in this study considering a return time of medium length. Furthermore, RVs of daily precipitation totals over $5,11,21$ or 31 days are investigated as indicators of longerterm wet periods. The GPD fit for each random sample, quantile threshold, aggregation level or reference period is only performed for data samples of more than 25 rainy days with rainfall larger $0.1 \mathrm{~mm}$ exceeding the quantile threshold. We are aware that this small sample size threshold might cause uncertainties in estimating GPD parameters. However, we decided to calculate daily rainfall extremes also for dry Mediterranean regions during summer and in the southern and eastern parts but to apply statistical methods that could alleviate the small sample problem (instead of omitting such regions): the method of L-moments for parameter estimation and a bootstrap sampling approach to evaluate RV uncertainties with regard to sampling errors (see above). Generally, we found rather good agreement between fitted GPD RVs and corresponding empirical quantiles from data samples. Sensitivity tests showed that stated differences are mostly smaller than 1.645 times the $\mathrm{RV}$ standard error, i.e. empirical quantiles lie within the $90 \%$ RV confidence intervals (not shown).

To solve the problem of comparing local rainfall stations with area-averaged model data, a dynamical-statistical WG is applied. The WG creates virtual station time series from gridded REMO precipitation, combining an orographic term, a stochastic term and a statistical matching of the probability density functions (PDFs) of daily precipitation from REMO towards station characteristics at 93 qualitycontrolled stations throughout the Mediterranean region. The approach is described in detail by Paeth and Diederich (2010): the larger-scale information of rainfall including 
the climate signal $p_{i}(t)$ of grid box $\mathrm{i}$ and day $\mathrm{t}$ come from REMO. A part of the spatial rainfall variability at meteorological stations within a REMO grid box arises from orographic effects which are represented by a linear regression between wind-ward and lee effects, i.e. the station anomaly vector of zonal and meridional orographic gradients respective to the corresponding REMO vector (both from SRTM elevation data) combined with daily wind vectors from ERA40, and station rainfall deviations from the regional mean (cf. Funk et al. 2003). The orographic term at station $\mathrm{j}$ is computed in multiplying the linear regression coefficient $b_{j}$, the station anomaly vector of orographic gradients $\vec{g}_{j}$ and the simulated REMO horizontal wind vectors $\vec{v}_{i}(t)$ . Corresponding correlations coefficients per station reach maxima of $0.20-0.35$, mostly significant at an error level of $5 \%$, i.e. the orographic term explains up to $4-12 \%$ of total rainfall variance. Its performance might be further enhanced if more Mediterranean stations were available per REMO grid box to improve the calculation of regional station rainfall means. The residual part which cannot be explained by orographic effects builds the stochastic term, i.e. random numbers $\varepsilon_{j}(t)$ are drawn from a normal distribution fitted to the residual time series. It stands for smallerscale convective rain events which are randomly distributed within a REMO grid box. After adding all mentioned components following

$\hat{p}_{j}(t)=p_{i}(t)+b_{j} \cdot \vec{g}_{j} \cdot \vec{v}_{i}(t)+\varepsilon_{j}(t)$

the resulting combined daily precipitation time series $\hat{p}_{j}(t)$ is split up into events below and above the $80 \%$ quantile, using the Gamma function and the GPD, respectively, for the PDF matching of the combined REMO daily rainfall distributions towards station characteristics (cf. Duda et al. 2001). Note that this mixture model might reveal uncertainties in parameter fitting due to the relatively low GPD threshold of $80 \%$ and the intrinsic discontinuity of the abrupt transition between both distributions. Both issues can affect the results of the PDF matching and might be solved by a weight function enabling a smoother transition (Vrac and Naveau 2007). However, we decided to choose this mixture model with abrupt transition because it has already been successfully applied to daily rainfall in Benin (Paeth and Diederich 2010) and performs similarly well for the Mediterranean area in this study (see Sect. 4.1). In accordance with the sample size threshold of the GPD analysis (see above), the fitting of the Gamma function and the GPD within the WG is only performed when more than 100 and 25 rainy days with rainfall larger $0.1 \mathrm{~mm}$ are available below and above the $80 \%$ quantile threshold, respectively.

Given the limited data base with 93 Mediterranean stations, only six REMO grid boxes contain multiple stations being essential for the computation of the orographic and stochastic terms: four in Galicia, Crete, Cyprus and Israel with two stations per grid box and two in Israel with five stations per grid box (cf. Fig 4, bottom right). Therefore, two WG versions are applied: a full version for the 18 stations in multi-station REMO grid boxes and a version with PDF matching only for all 93 stations. However, we suppose that the impact of the PDF matching probably exceeds that of the rather less influential orographic term (see above) even in the full WG. Both versions are set up with observations during 1960-2000 and applied to gridded REMO data separately per month during 1961-2050 for both emissions scenarios. Rainfall extremes of virtual stations are again derived from fitting GPD functions. Generally, the WG has no specific range of scales and could also be applied to the coarser ECHAM5/MPI-OM resolution which was not performed in this study because we aimed at applying the WG only to the "best" given model with highest resolution.

\section{Results}

\subsection{Validation of the weather generator}

In Fig. 1 two characteristics of daily precipitation during 1960-2000 are compared between one ensemble member from REMO, observed station data and virtual station data from the WG at selected Mediterranean locations: the percentage of dry days with rainfall amount smaller than $0.1 \mathrm{~mm}$ and the average intensity of daily rainfall extremes above the $80 \%$ quantile. In July, the typical discrepancies between area-averaged model and local station rainfall become apparent (Fig. 1, top left and right): REMO produces too many rainy days of low intensity and underestimates precipitation extremes. The WG is able to overcome this deficiency with only marginal differences between both WG versions. Thus, the improvement is mainly reached by PDF matching with only minor impacts of the orographic and stochastic terms. These results are mostly robust and do not change substantially at different station sites. In the eastern and some western parts, the WG cannot be applied in summer because the criterion mentioned in Sect. 3 is not fulfilled due to the low number of rain events.

In January, REMO shows even smaller numbers of dry days compared to stations, such that improvements by the WG are even more efficient, but the full WG reveals slightly too many dry days over few eastern Mediterranean stations probably due to larger uncertainties in the context of smaller data samples (Fig. 1, bottom left). Besides typical underestimations of station extreme rainfall intensities, REMO shows even overestimated intensities over some locations at elevated mountain sites which are as well clearly calibrated by the WG (Fig. 1, bottom right). 
Fig. 1 Characteristics of daily precipitation at selected locations (western to eastern Mediterranean area from left to right in bar plots) compared between the first REMO ensemble member (blue), PDF matching (orange), full WG (red) and original station distributions (black) in July (top) and January (bottom) over the reference period 1960-2000, (oro) marks stations with orographic and stochastic terms
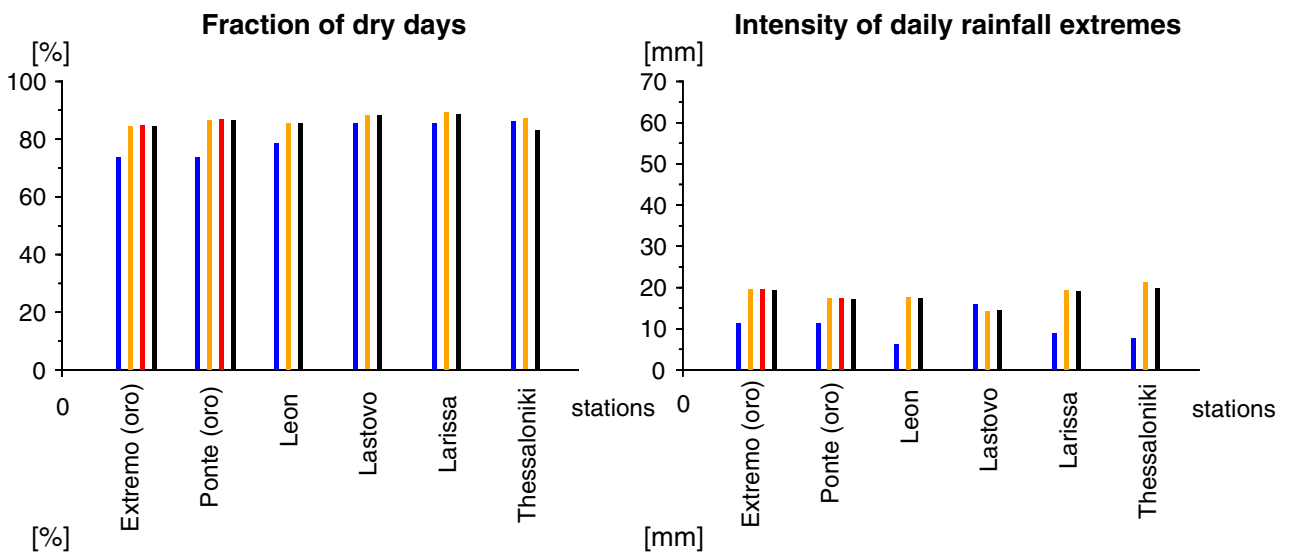
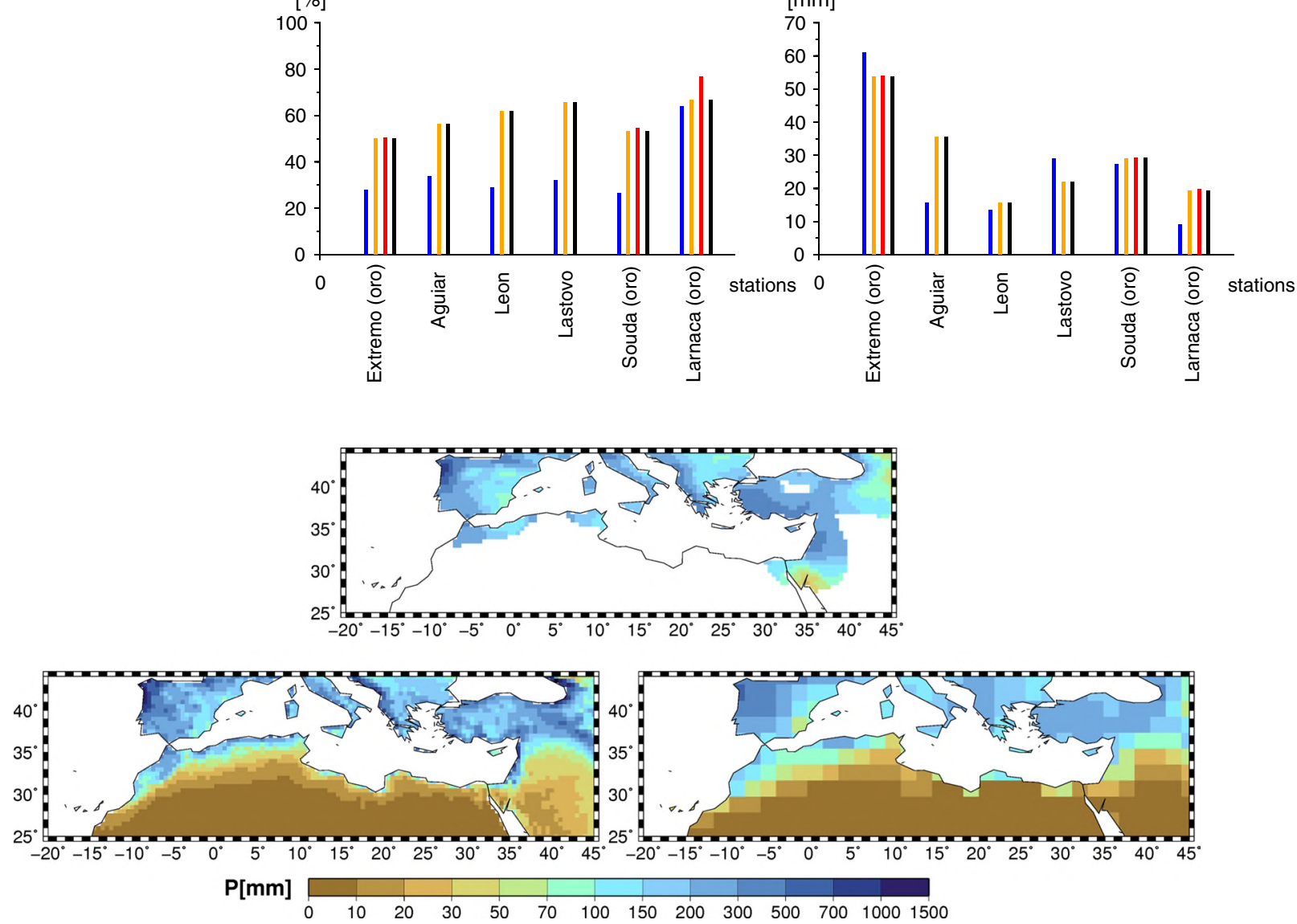

Fig. 2 Comparison of winter precipitation totals averaged over the period 1961-1990 between REMO ensemble mean (bottom left), ECHAM5/MPI-OM ensemble mean (bottom right) and E-OBS (top)

Overall, the WG is also able to adjust overestimated mean annual rainfall totals of REMO over some Mediterranean regions to lower station totals (not shown).

\subsection{Validation of simulated precipitation extremes}

First of all, the climatology of winter precipitation over the period 1961-1990 is compared between ECHAM5/MPIOM, REMO and gridded observations (Fig. 2). It is obvious that dynamical downscaling improves the spatial representation of Mediterranean precipitation and removes some systematic errors of the global model, e.g. underestimations over Italy, the Atlas Mountains and the Near East. The RCM is characterized by even more spatial details than the gridded observations, especially over Spain and Turkey. This could probably be interpreted as an indicator that some orographic effects of the complex topographic and land-sea contrasts in the Mediterranean area are better accounted for in REMO simulations than in spatially interpolated E-OBS data. However, REMO tends to 

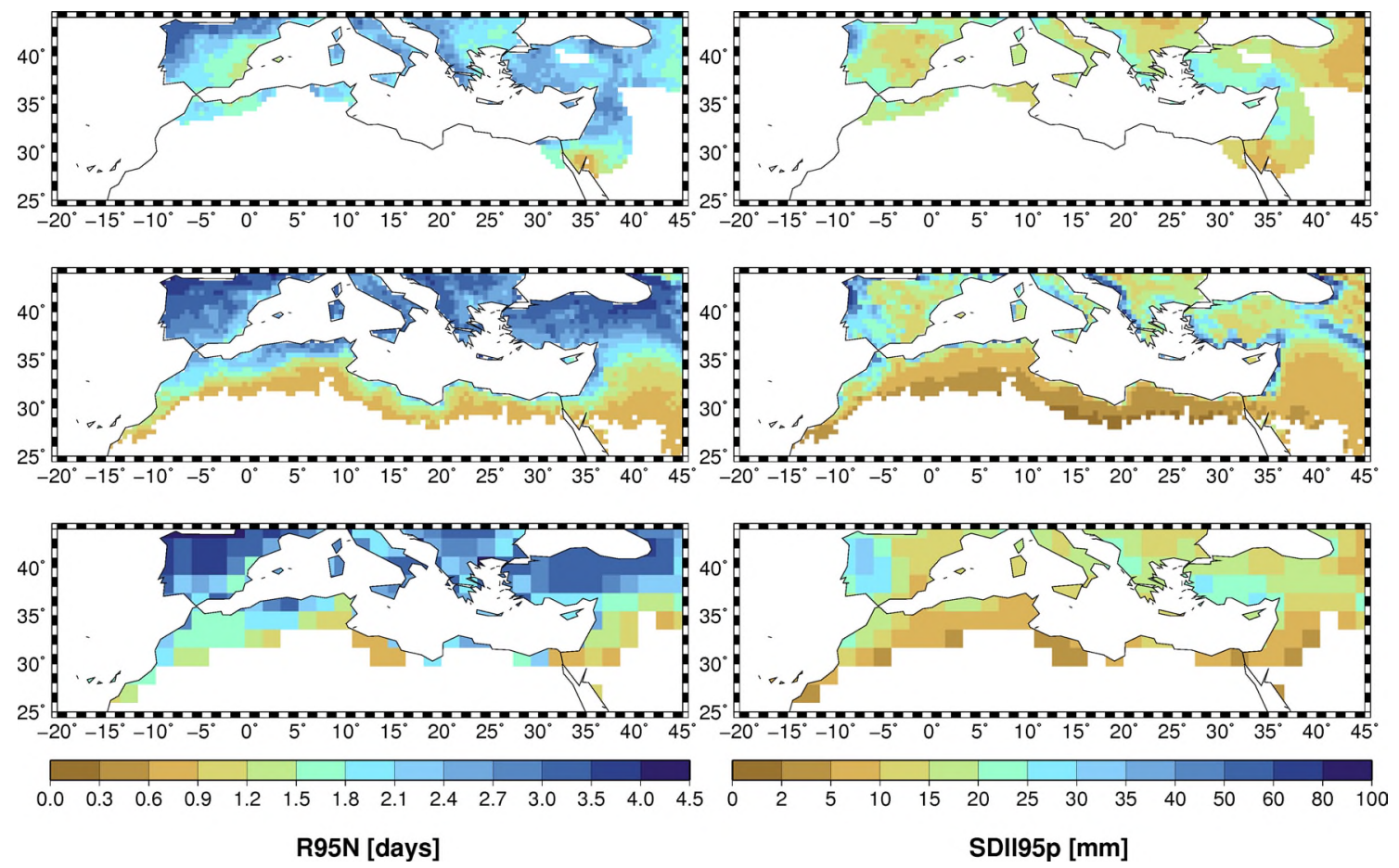

Fig. 3 Comparison of quantile-based indices of extreme daily winter precipitation during the period 1961-1990 between E-OBS (top), REMO ensemble mean (middle) and ECHAM5/MPI-OM ensemble mean (bottom): number of rainy days exceeding the $95 \%$ quantile (R95N, left) and corresponding mean daily intensity (SDII95p, right)
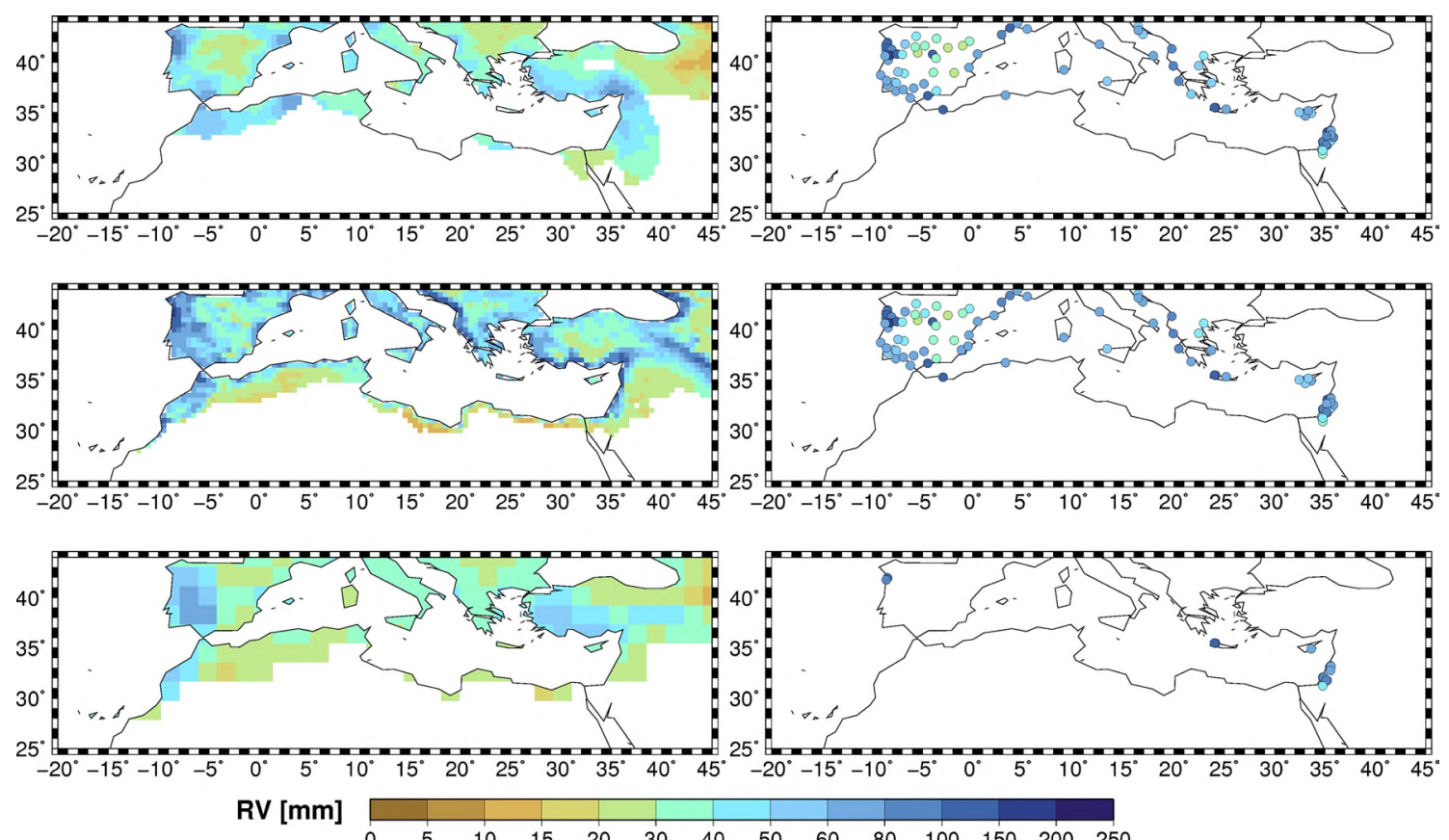

Fig. 4 Comparison of GPD-based 20-year RVs of extreme daily winter precipitation during the period 1961-1990 between E-OBS (top left), REMO ensemble mean (middle left), ECHAM5/MPI-OM ensemble mean (bottom left), station data (top right), PDF matching (middle right) and full WG (bottom right) 
overestimate gridded E-OBS rainfall over some mountain ranges. This added value of REMO can be confirmed for summer precipitation which is strongly underestimated by ECHAM5/MPI-OM over the whole area (not shown).

Figure 3 displays the quantile-based precipitation extreme indices of E-OBS, REMO and ECHAM5/MPIOM for winter 1961-1990. Summer is not depicted explicitly but shows similar results with even more agreement between models and observations. The $95 \%$ quantile of daily rainfall upon which these indices are based is not shown since it depicts rather similar patterns to seasonal totals (cf. Hertig et al. 2012a). R95N describes the frequency of rainfall extremes (Fig. 3, left): Observations show 1-3.5 extreme rainfall days in winter and 0.52.5 days in summer (averaged over 1961-1990). In winter, both models overestimate the observed R95N over southern Europe and Turkey by $0.5-1$ days while some underestimation occurs over the Near East. In summer, R95N is slightly overestimated over northern Spain and Turkey whereas grid boxes over Africa and the Arabian Peninsula cannot be evaluated due to the low number of rain events. The overestimation of winter extremes in some parts of the northern Mediterranean area is related to an inflated number of simulated rainy days in both models compared to observations because the spatial distribution of R95N follows approximately that of the number of rainy days owing to the selected type of analysis (see Sect. 3).

As a measure of extreme precipitation intensity, the observed SDII $95 \mathrm{p}$ ranges between 5 and $20 \mathrm{~mm}$ over southern Europe and Turkey in summer and $5-50 \mathrm{~mm}$ in winter with maxima over Galicia (Fig. 3, right). In winter, ECHAM5/MPIOM mostly agrees with observations but noticeably underestimates the observed intensities over mountain ranges with maximum precipitation extremes. REMO stands out due to its small-scale topographic details of extreme intensities but tends to overestimate the observed SDII95p, especially over regions with particularly heavy precipitation like e.g. Galicia, the western Balkans, southern Turkey and coastal Israel. In summer, discrepancies between models and observations are smaller. While the underestimated extreme intensities in ECHAM5/MPI-OM can probably be explained by the coarsegrid representation of orographic effects, the overestimation by REMO is debatable: positively speaking it could reflect a shortcoming of gridded (spatially interpolated) observational data which smooth extreme rainfall intensities compared to local stations, especially at higher-elevation mountain sites (cf. Haylock et al. 2008).

The GPD-based winter precipitation extremes during 1961-1990 are compared between all considered data sets in Fig. 4. The RVs refer to a RT of 20 years for daily precipitation. Observed RVs range from less than $15 \mathrm{~mm} /$ day over eastern Turkey to more than $100 \mathrm{~mm} /$ day over the Iberian Peninsula and southern Turkey (Fig. 4, left).
The spatial patterns and the relative differences between E-OBS, REMO and ECHAM5/MPI-OM are basically consistent with Fig. 3: observed winter heavy precipitation is underestimated by ECHAM5/MPI-OM and overestimated by REMO, especially over mountain ranges with maximum rainfall extremes. In summer, ECHAM5/MPI-OM underestimates observations over large parts of the northern Mediterranean area. The relative RV uncertainty (RV standard error divided by RV magnitude, i.e. daily extreme minus daily sum) is smallest over southern Europe and Turkey in winter $(6-10 \%)$ and largest over northern Africa in both seasons and the near and Middle East in summer (30$80 \%$ ) where many grid boxes cannot be evaluated due to low numbers of rain events (not shown).

In terms of the real and virtual station data (Fig. 4, right), we can state an excellent agreement between the observations and the data produced by the WG. Largest differences lie around $10-17 \mathrm{~mm}$, but no clear spatial pattern of differences can be stated except for some underestimations in the WG data over the Near East. Again, the orographic and stochastic terms do not lead to a noticeably different result than the PDF matching alone. Maximum values $(150 \mathrm{~mm} /$ day) are found over coastal Spain and Portugal and minimum values $(30 \mathrm{~mm} /$ day) mainly over central Spain. Precipitation extremes at station level are mostly underestimated by the gridded data sets. The large REMO extremes are closest to station data. This gives support to the hypothesis that orographic effects are better represented in REMO than in the statistically interpolated E-OBS data. Indeed, precipitation extremes from the RCM often range between E-OBS and station data. In summer, the results are equivalent, but a much smaller number of stations (mainly over Portugal, Spain and the Balkans) can be analysed due to the low number of rainy days. The relative RV uncertainty for station and virtual station data is mostly larger than that for gridded data because of smaller sample sizes (not shown).

In order to highlight the systematic differences between precipitation extremes from the GCM, RCM, WG and different observations, Fig. 5 compares 20 -year RVs of daily winter and summer precipitation at selected station sites across the Mediterranean region during 1961-1990. Station data and WG data are very close to each other, REMO is generally more consistent with stations than the lower E-OBS extremes, and ECHAM5/MPI-OM diverges considerably towards clearly underestimated extremes, especially in summer. Thus, the added value of REMO is more pronounced during the warm than during the cold season when heavy precipitation is more linked to larger-scale atmospheric dynamics.

\subsection{Projection of future simulated precipitation extremes}

As the RCM is more consistent with observed precipitation totals and extremes than the GCM, the projection of future 


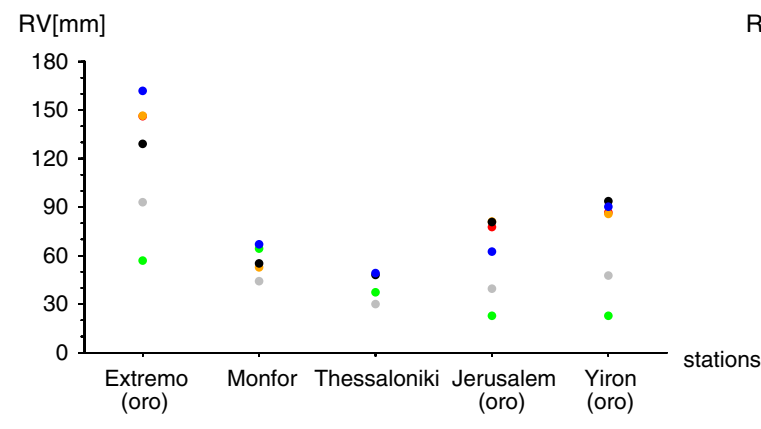

Fig. 5 Comparison of GPD-based 20-year RVs of extreme daily winter (left) and summer (right) precipitation during the period 1961-1990 between station data (black), PDF matching (orange), full WG (red), E-OBS (grey), REMO ensemble mean (blue) and

changes in heavy rainfall relies mainly on REMO (Fig. 6). Under the A1B emissions scenario, statistically significant negative trends of seasonal precipitation totals prevail over the southern and northern Mediterranean region in winter and summer during 1961-2050, respectively. In winter, some significant increases are simulated over northern Turkey and the Caucasus region whereas smaller increases over the Dinaric Alps and parts of northern Spain do not reach significance (Fig. 6, top row).

Changes in the frequency of heavy rain events between 2021-2050 and 1961-1990 draw a less coherent picture (Fig. 6, second row): R95N mainly decreases over the southern areas in winter and the northern part in summer according to the decline of seasonal totals. In winter, the Iberian Peninsula, the northern Balkans and Turkey are characterized by more frequent extreme events while total precipitation is mainly decreasing. This process is hardly significant due to the high level of internal precipitation variability but constitutes an alarming tendency in terms of simultaneously increasing drought and flood risks. The changes in SDII95p mainly reflect the pattern of R95N (Fig. 6, third row). Yet even less changes are statistically significant, increasing extreme rainfall intensities prevail over the northern Balkans in summer, and more small-scale details are simulated over mountain ranges, e.g. the Balkans and the Caucasus, compared to R95N.

The pattern of changes in 20-year RVs is similar but not identical to the quantile-based indices of daily precipitation extremes (Fig. 6, forth row): larger regions of increasing RVs are found compared to R95N and SDII95p, e.g. Italy and the Near East in winter and the Balkans and central Turkey in summer, which are as well opposed to decreasing rainfall totals. This demonstrates that the definition of extreme events plays a role in the assessment of future climate change. In general, the pattern is quite heterogeneous in space, and none of the changes are statistically significant. This reflects the increased uncertainty of

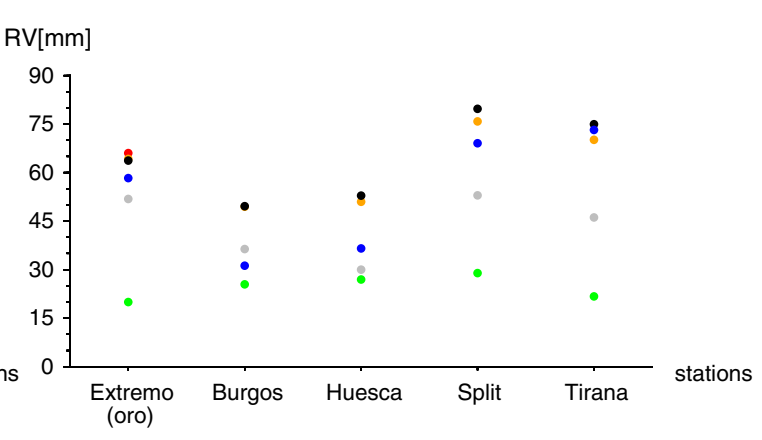

ECHAM5/MPI-OM ensemble mean (green) at selected Mediterranean station sites, (oro) marks stations with orographic and stochastic terms

the GPD-based RV estimate in the light of small samples which broadens the confidence intervals of RVs over the bootstrap samples and enlarges the overlapping of presentday and future reference periods (see Sect. 3). Note that due to the overall reduction of summer precipitation across the Mediterranean region the sample sizes for the GPD fit are even smaller in the future than in the present-day period and thus, the relative RV uncertainty mostly increases (not shown).

This result is basically corroborated by the GPD-based 20-year RVs from the virtual station data (Fig. 6, fifth and sixth row). Compared to Fig. 4, all applicable virtual stations in Portugal, Spain and the Balkans have been removed in summer due to a low number of rainy days, and no single station remains for both WG versions. The future Mediterranean climate is mainly characterized by more intense rain events in winter, especially over the Iberian Peninsula where station density is highest. Some decreases are found over eastern Spain, Greece and southern Israel. Again, none of these changes are significant. Only small differences can be stated between PDF matching and full WG, e.g. over Crete or southern Israel in winter, implying that the interaction between fine-scale orographic gradients and changing wind directions (see Sect. 3) does not play a major role. Compared to gridded rainfall extremes from REMO, the virtual stations from the WG show up with slightly stronger increases in winter. If a smaller sample size threshold for the GPD fit in summer is chosen (which strongly increases the relative RV uncertainty), virtual stations reveal similar changes to REMO extremes but less decreases, especially over Spain (not shown).

Overall, ECHAM5/MPI-OM depicts mostly smaller intensities and less small-scale topographic details of future changes in rainfall totals and extremes than REMO. Concerning rainfall totals and extreme frequencies, the B1 emissions scenario reveals mostly smaller drying patterns than A1B but stronger wetting over the northern parts in 


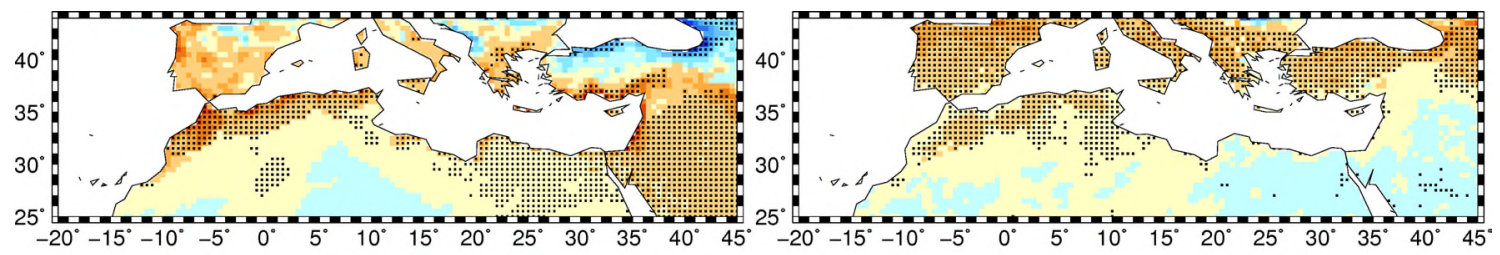

$\mathrm{P}[\mathrm{mm} / 90$ years]

$-300-250-200-150-100-60-30-10 \quad 0 \quad 10 \quad 30 \quad 60 \quad 100 \quad 150200250300$

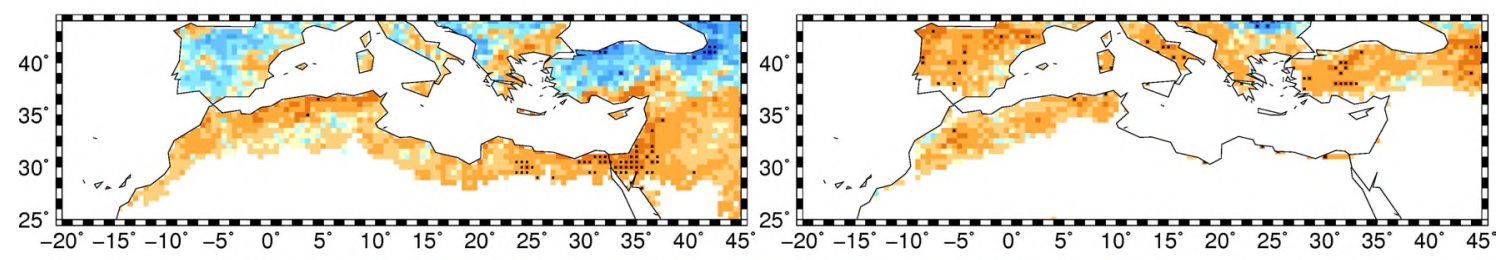

R95N [days]

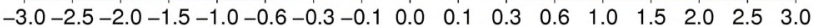

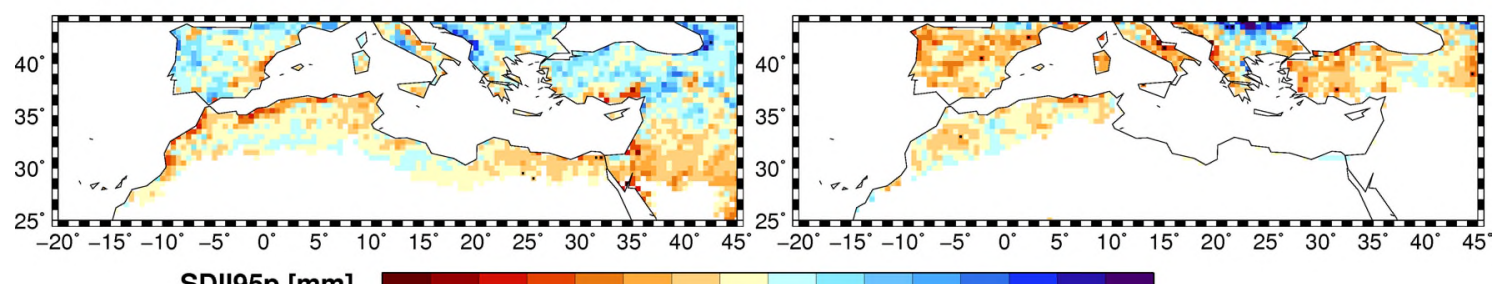

SDII95p [mm]
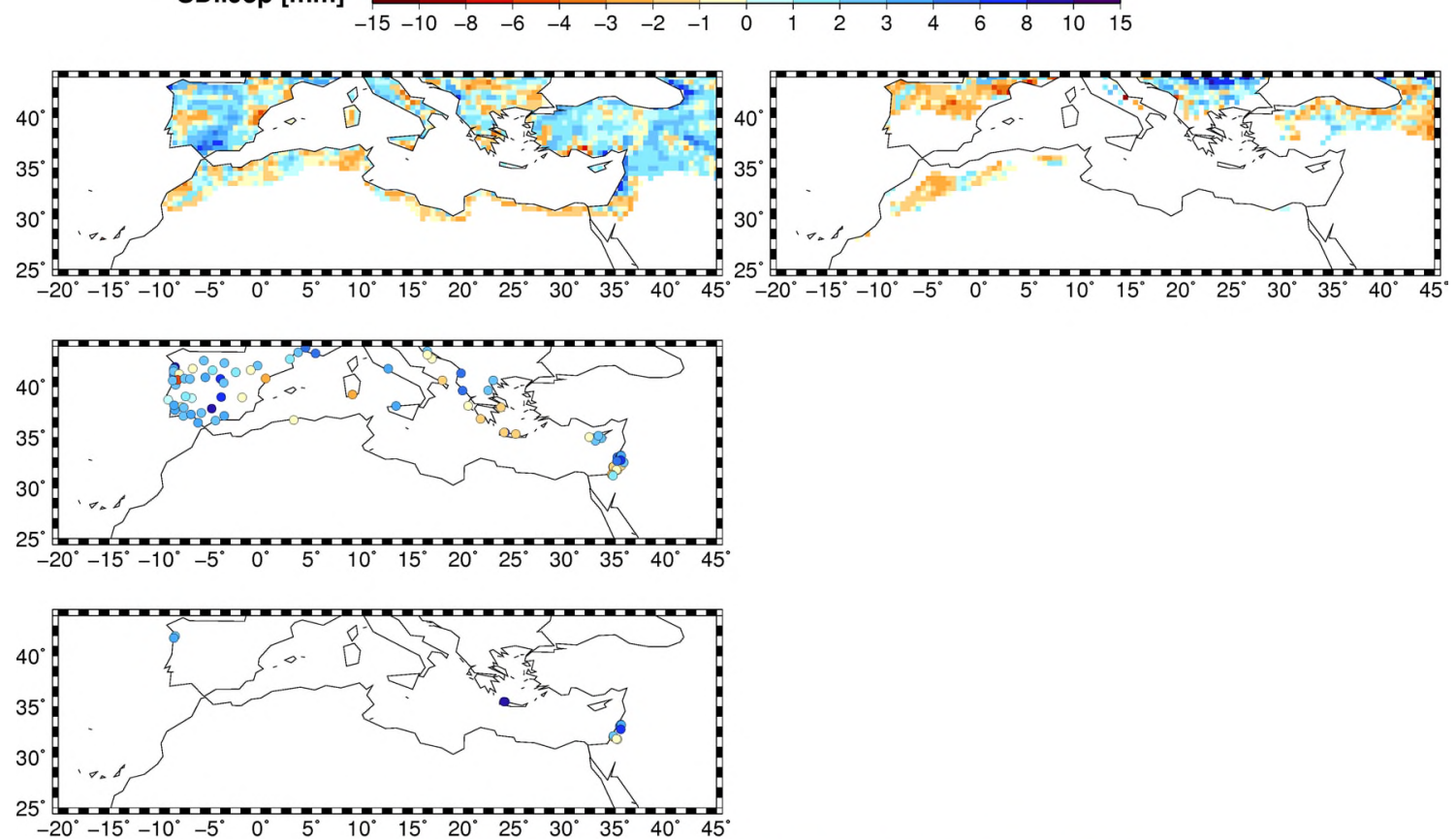

$\mathrm{RV}[\mathrm{mm}]$

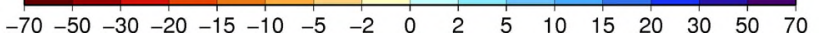

Fig. 6 Greenhouse gas related changes in precipitation totals and extremes during winter (left) and summer (right) as simulated by REMO ensemble mean under the A1B emissions scenario: linear trends of seasonal sums over the period 1961-2050 (first row), changes in R95 N between the reference periods 2021-2050 and
1961-1990 (second row), changes in SDII95p between the same reference periods (third row) and changes in GPD-based 20-year RVs of daily precipitation extremes from REMO (fourth row), PDF matching (fifth row) and full WG (sixth row). Statistically significant changes at an error level of $5 \%$ are marked by black dots and bold circles 


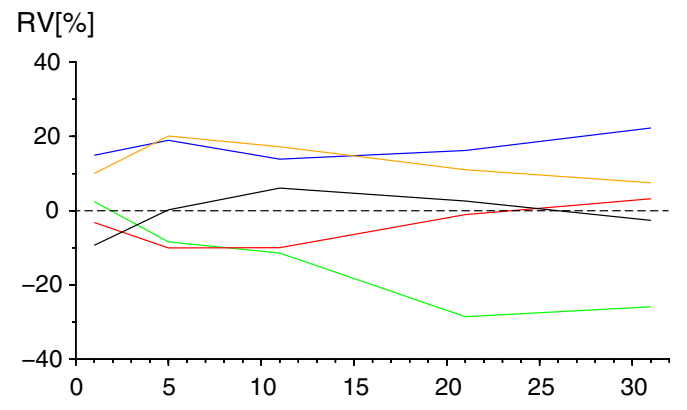

Fig. 7 Greenhouse gas related relative changes (\%) in GPD-based 20-year RVs of precipitation extremes for aggregation levels between 1 and 31 days during winter (left) and summer (right) between the reference periods 2021-2050 and 1961-1990 compared to 1961-

winter. However, for extreme rainfall intensities (SDII95p, RVs, WG), similar patterns with only small differences are found (not shown). Thus, the political scope of action depends on which variable or season is analysed.

To have a closer look at changes in extreme precipitation for different aggregation levels, i.e. counting events over consecutive days, GPD-based RVs of REMO are investigated for regional-means $(200 \times 200 \mathrm{~km})$ over selected Mediterranean regions. Figure 7 shows relative future changes (\% w.r.t. the period 1961-1990) estimated for the period 2021-2050 under the A1B scenario. During summer, the projected changes for almost all aggregation levels of daily precipitation reveal equally strong or even stronger relative decreases than those for daily extremes over all considered regions which can be interpreted as an indicator of drier periods during summer. In Morocco, the relative changes clearly increase with the aggregation level of daily summer precipitation implying that the intensity of rainfall accumulated over 21-31 days decreases more than for cumulative precipitation over a few days. In winter, the picture is more diverse. Similar results are found in Morocco, but in Spain the flood risk may be enhanced because heavy rainfall over 31 consecutive days tends to increase slightly more than at the level of daily events. In Israel and the Balkans, relative changes even switch their sign for different aggregation levels. Note that the statistical significance of future changes increases towards higher aggregation levels probably indicating that radiative forcing impacts stronger on rainfall extremes on the monthly than on the daily scale (not shown).

\section{Discussion}

This study has addressed three main issues: (1) a systematic assessment of precipitation extremes in the Mediterranean basin using two different approaches in extreme value statistics, i.e. quantile-based indices and fitting of

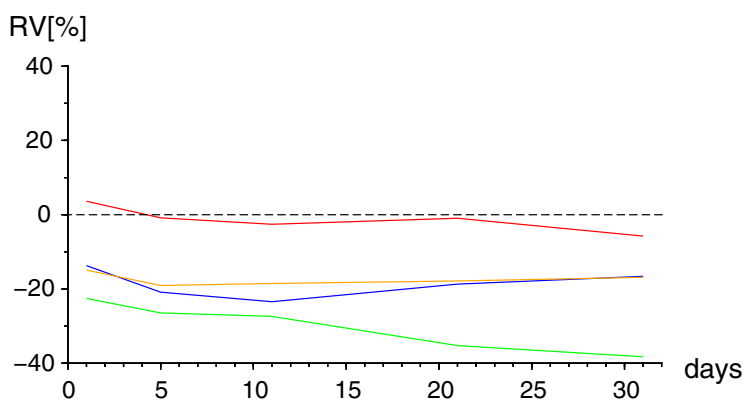

1990 extremes for selected Mediterranean regions (Spain: blue, Morocco: green, the Balkans: red, Turkey: orange, Israel: black) as simulated by REMO ensemble mean under the A1B emissions scenario

the theoretical GPD, and a WG as a tool of model output statistics, (2) the added value of dynamical downscaling from a driving GCM to a nested RCM in a qualitative comparison with the observed pattern and characteristic of precipitation extremes and (3) projections of future changes in extreme precipitation under enhanced radiative forcing. Concerning dynamical downscaling, the RCM REMO at $0.5^{\circ}$ resolution reveals some added value compared to the global GCM ECHAM5/MPI-OM at $1.875^{\circ}$ resolution: both the climatology of winter and summer precipitation and heavy rain events are characterized by more spatial details in REMO compared to ECHAM5/MPI-OM and even gridded observations. Thus, the RCM accounts more realistically for the distinct topographic heterogeneity and the land-sea contrasts in the Mediterranean region. Furthermore, ECHAM5/MPI-OM clearly underestimates the observed totals and extremes over mountains and in summer. REMO tends to overestimate the gridded E-OBS data over some mountain ranges in winter but is substantially closer to local station information, mostly ranging between both observational datasets. Therefore, the added value of REMO compared to ECHAM5/MPI-OM is more striking in summer when local convective rainfall prevails than in winter when precipitation is rather connected to large-scale atmospheric dynamics. Similar improvements of GCM biases by RCMs have been reported by Jacob et al. (2007), Giorgi and Lionello (2008) and Giorgi and Coppola (2009) for rainfall totals and by Christensen and Christensen (2003), Frei et al. (2006) and Gao et al. (2006) for rainfall extremes. Hertig et al. (2012a) compared the prevailing REMO simulations with the statistical downscaling of quantile-based winter extremes and concluded that both methods improve coarse-grid ECHAM5/MPI-OM extremes: dynamical downscaling simulates more realistic intensities but overestimates frequencies and statistical downscaling produces more realistic frequencies but underestimates intensities compared to local stations. 
The application of the dynamical-statistical WG improves the representation of precipitation extremes considerably. The resulting virtual station data overcome the typical phenomenon that area-averaged model output overestimates the number of weak rainfall events while underestimating extreme precipitation compared to local stations (cf. Lebel et al. 2000; Zolina et al. 2004; Haylock et al. 2008). This improvement is mainly achieved by PDF matching. The orographic and stochastic terms can only be calculated for some Mediterranean grid boxes due to the low density of given station data and the physical part of the WG stands back from the statistical component even in the full WG version (see Sect. 3). This implies that the virtual station data are strongly influenced by the observations which partly explains the good agreement between real and virtual station characteristics. Paeth and Diederich (2010) found similar improvements when applying the WG to daily precipitation over tropical West Africa. Thus, the WG describes a final downscaling step from regional to local scale, particularly required for small-scale rainfall extremes in regions of large topographic contrasts. The virtual station data produced by the WG represent a valuable basis for impact studies, e.g. on river discharge, soil erosion or agriculture (Wilks 1999; Busche et al. 2005).

In terms of future changes in precipitation extremes, the picture is spatially heterogeneous, but some coherent structures can be identified which are consistent across the different extreme indices, the GPD-based estimates and the WG-calibrated REMO output: in summer, a prominent drying prevails mainly over the northern parts of the Mediterranean basin. This drying comes along with a weakening of heavy rain events but with some exceptions, especially over Southeast Europe where precipitation extremes intensify considerably. In winter which represents the main rainy season in the Mediterranean basin, the situation is different: the majority of the land grid boxes may also experience a drying, most significant over the southern areas, but positive precipitation trends predominate around the Black Sea and in parts of the Balkans and northern Spain. In addition to weakening rainfall extremes over the southern part, there is a distinct tendency towards more intense precipitation extremes in many northern Mediterranean regions, particularly over the Iberian Peninsula and Turkey. Thus, regions with reduced precipitation amounts are confronted with heavier individual events, enhancing the risk of both droughts and floods which may cause soil erosion, landslides, crop failures or water shortages. This may be explained by the following physical mechanisms: decreasing rainfall totals may be caused by a greenhouse gas induced poleward expansion of the Azores high and reduced influence of large-scale mid-latitude westerly winds (Coppola et al. 2005; Christensen et al. 2007), while enhanced small-scale extremes may result from more local thermodynamic effects in a warmer atmosphere with increasing water vapour content and static instability. However, this is still not well understood and describes an open issue of current research. Projected changes in extreme rainfall aggregated over several consecutive days reveal some indications for enhanced winter flood risk over Spain as well as drier periods over Morocco in winter and over all considered Mediterranean regions in summer.

These findings basically agree with previous studies on GCM and RCM projections for the Mediterranean area in terms of seasonal precipitation trends (Christensen and Christensen 2007; Giorgi and Lionello 2008; Giorgi and Coppola 2009; Goodess et al. 2009). Concerning rainfall extremes, previous works have suggested a variety of possible future pathways based on different models and statistical approaches (e.g. Paeth and Hense 2005; Frei et al. 2006; Beniston et al. 2007). Our analysis gives support to those studies which have revealed Mediterranean regions with decreasing totals but increasing extremes (e.g. Christensen and Christensen 2003; Semmler and Jacob 2004; Gao et al. 2006; Goubanova and Li 2007; Kharin et al. 2013; Toreti et al. 2013). Statistical downscaling (likewise forced by ECHAM5/MPI-OM) rather agrees with REMO projections of quantile-based winter extreme frequencies but rather disagrees with the RCM in simulating strongly heterogeneous changes of winter extreme intensities (Hertig et al. 2012a). An advanced version considering both large-scale circulation and thermodynamic conditions simulates similar changes to REMO extremes but more expanded increases of winter and summer totals depicting only few regions with decreasing totals but increasing extremes (Hertig et al. 2012b). This highlights the partly strong deviations between different downscaling approaches.

The use of quantile-based versus GPD-based indices of extreme precipitation leads to similar results in dynamical downscaling and future changes (see above), but some differences can be stated, e.g. the GPD-based RVs reveal larger regions of increasing rainfall extremes in future times than quantile-based indices. Thus, the choice of extreme value definitions plays a noticeable but not a crucial role in the assessment of present-day and future extreme events. In choosing the appropriate method for a certain application, one has to keep in mind that empirical quantiles are limited to the length of the given sample period, but the fitting of a theoretical distribution allows the extrapolation to RTs beyond this length (even if corresponding domains of uncertainty are clearly increased). However, both methods suffer from large sampling errors due to small datasets. Thus, the use of statistical measures to quantify corresponding uncertainties such as bootstrap sampling approaches is recommended, particularly for small data samples, e.g. summer rainfall extremes over the Mediterranean area. Finally, we advise the application of the WG 
in regions of large topographic contrasts which strongly improves present-day Mediterranean rainfall extremes (see above) and reveals even more extended increases of future extremes compared to gridded model data.

In order to tackle the problem of changing precipitation extremes in the Mediterranean area, more work is still needed. An important extension is the use of multi-model ensembles of GCMs and RCMs to capture the uncertainties arising from different climate models. A promising step into this direction is the MED-CORDEX initiative (e.g. Ruti et al. 2010). Enhanced RCM resolution will further improve the representation of small-scale rainfall structures in regions with distinct topographic contrasts. The database of 93 quality-controlled rainfall stations across the Mediterranean area needs to be strictly enlarged for an appropriate application of the WG, since data availability from meteorological services is often restricted. The orographic term could be applied to more stations and its performance (explained variance) could probably be enhanced if more stations per REMO grid box were available. The WG may be further improved by including additional factors besides orographic gradients, e.g. continentality, elevation and distance from the North Atlantic storm track.

Acknowledgments This study has been carried out in the framework of the KLIWEX-MED project (Climate Change and Extreme Events in the Mediterranean Basin) funded by the German Research Foundation (DFG) under Grants PA 1194/3 and JA 831/7. We acknowledge the E-OBS dataset from the EU-FP6 project ENSEMBLES (http://www.ensembles-eu.org/) and the dataset from the ECA\&D project (http://eca.knmi.nl). The ECHAM5/MPI-OM experiments have been kindly provided by the Max-Planck Institute for Meteorology. We thank the ECMWF and the USGS for providing the ERA40 reanalysis data and the SRTM Finished Grade data, respectively. Finally, we thank the reviewers for their fruitful comments and suggestions.

\section{References}

Alpert P (2002) The paradoxical increase of Mediterranean extreme daily rainfall in spite of decrease in total values. Geophys Res Lett 29:1-4

Beniston M, Stephenson DB, Christensen OB, Ferro CAT, Frei C, Goyette S, Halsnaes K, Holt T, Jylhä K, Koffi B, Palutikof J, Schöll R, Semmler T, Woth K (2007) Future extreme events in European climate: an exploration of regional climate model projections. Clim Change 81:71-95

Boberg F, Christensen JH (2012) Overestimation of Mediterranean summer temperature projections due to model deficiencies. Nat Clim Change 2:433-436

Busche H, Hiepe C, Diekkrüger B (2005) Modelling the effects of changes in landuse and precipitation on hydrological and erosive processes in a sub-humid African catchment. In.Proc 3rd Int SWAT Conf 25:434-443

Changnon SD (2003) Measures of economic impacts of weather extremes. Bull Am Meteorol Soc 84:1231-1235

Christensen JH, Christensen OB (2003) Severe summertime flooding in Europe. Nature 421:805-806
Christensen JH, Christensen OB (2007) A summary of the PRUDENCE model projections of changes in European climate by the end of this century. Clim Change (Prudence Special Issue) $81: 7-30$

Christensen JH, Hewitson B, Busuioc A, Chen A, Gao X, Held I, Jones R, Kolli RK, Kwon W-T, Laprise R, Magaña Rueda V, Mearns L, Menéndez CG, Räisänen J, Rinke A, Sarr A, Whetton P (2007) Regional climate projections. In: Solomon S, Qin D, Manning M, Chen Z, Marquis M, Averyt KB, Tignor M, Miller HL (eds) Climate Change 2007: The physical science basis contribution of working group I to the fourth assessment report of the intergovernmental panel on climate change. Cambridge University Press, Cambridge, pp 847-940

Coles S (2001) An introduction to statistical modeling of extreme values. Springer, Berlin

Coppola E, Kucharski F, Giorgi F, Molteni F (2005) Bimodality of the North Atlantic Oscillation in simulations with greenhouse gas forcing. Geophys Res Lett 32:2-5

Del Río S, Herrero L, Fraile R, Penas A (2010) Spatial distribution of recent rainfall trends in Spain (1961-2006). Int J Climatol 31:656-667

Della-Marta PM, Wanner H (2006) A method of homogenizing the extremes and mean of daily temperature measurements. J Clim 19:4179-4197

Della-Marta PM, Haylock MR, Luterbacher J, Wanner H (2007) Doubled length of western European summer heat waves since 1880. J Geophys Res 112:1-12

Deque M, Somot S (2008) Analysis of heavy precipitation for France using high resolution ALADIN RCM simulations. Idöjaras Q J Hung Meteorol Serv 112:179-190

Diffenbaugh NS, Pal JS, Giorgi F, Gao X (2007) Heat stress intensification in the Mediterranean climate change hotspot. Geophys Res Lett $34: 1-6$

Duda RO, Hart PE, Stork DG (2001) Pattern classification, 2nd edn. Wiley, New York

Efthymiadis D, Goodess CM, Jones PD (2011) Trends in Mediterranean gridded temperature extremes and large-scale circulation influences. Nat Hazards Earth Syst Sci 11:2199-2214

Farr TG, Rosen PA, Caro E, Crippen R, Duren R, Hensley S, Kobrick M, Paller M, Rodriguez E, Roth L, Seal D, Shaffer S, Shimada J, Umland J (2007) The shuttle radar topography mission. Rev Geophys 45:RG2004, 1-43

Fischer EM, Schär C (2010) Consistent geographical patterns of changes in high-impact European heatwaves. Nat Geosci 3:398-403

Frei C, Schöll R, Fukutome S, Schmidli J, Vidale PL (2006) Future change of precipitation extremes in Europe: intercomparison of scenarios from regional climate models. J Geophys Res 111:D06105, 1-22

Funk C, Michaelsen J, Verdin J, Artan G, Husak G, Senay G, Gadain H, Magadazire T (2003) The collaborative historical African rainfall model: description and evaluation. Int J Climatol 23:47-66

Gao X, Pal JS, Giorgi F (2006) Projected changes in mean and extreme precipitation over the Mediterranean region from a high resolution double nested RCM simulation. Geophys Res Lett $33: 2-5$

García JA, Gallego MC, Serrano A, Vaquero JM (2007) Trends in block-seasonal extreme rainfall over the Iberian Peninsula in the second half of the twentieth century. J Clim 20:113-130

García-Herrera R, Hernández E, Barriopedro D, Paredes D, Trigo RM, Trigo IF, Mendes MA (2007) The outstanding 2004/05 drought in the Iberian Peninsula: associated atmospheric circulation. J Hydrometeorol 8:483-498

García-Herrera R, Díaz J, Trigo RM, Luterbacher J, Fischer EM (2010) A review of the European summer heat wave of 2003. Crit Rev Environ Sci Technol 40:267-306 
Giorgi F (2006) Climate change hot-spots. Geophys Res Lett 33:1-4 Giorgi F, Coppola E (2009) Projections of twenty-first century climate over Europe. Eur Phys J Conf 1:29-46

Giorgi F, Lionello P (2008) Climate change projections for the Mediterranean region. Glob Planet Change 63:90-104

Goodess CM, Jones PD (2002) Links between circulation and changes in the characteristics of Iberian rainfall. Int J Climatol 22:1593-1615

Goodess CM, Jacob D, Deque M, Guttierrez JM, Huth R, Kendon E, Leckebusch GC, Lorenz P, Pavan V (2009) Downscaling methods, data and tools for input to impact assessments. In: Van der Linden P, Mitchell JFB (eds) Summary of research and results from the ENSEMBLES project. Met Office Hadley Centre, Exeter, pp 59-78

Goubanova K, Li L (2007) Extremes in temperature and precipitation around the Mediterranean basin in an ensemble of future climate scenario simulations. Glob Planet Change 57:27-42

Haylock MR, Hofstra N, Klein Tank AMG, Klok EJ, Jones PD, New M (2008) A European daily high-resolution gridded data set of surface temperature and precipitation for 1950-2006. J Geophys Res 113:D20119, 1-12

Hertig E, Seubert S, Jacobeit J (2010) Temperature extremes in the Mediterranean area: trends in the past and assessments for the future. Nat Hazards Earth Syst Sci 10:2039-2050

Hertig E, Paxian A, Vogt G, Seubert S, Paeth H, Jacobeit J (2012a) Statistical and dynamical downscaling assessments of precipitation extremes in the Mediterranean area. Meteorol Z 21:61-77

Hertig E, Seubert S, Paxian A, Vogt G, Paeth H, Jacobeit J (2012b) Changes of total versus extreme precipitation and dry periods until the end of the 21st century: statistical assessments for the Mediterranean area. Theor Appl Climatol 111:1-20

Hoff H (2008) CIRCE Research Line 7-Climate Vulnerability of Mediterranean Ecosystems. CIRCE EU Project

Hosking J (1990) L-moments: analysis and estimation of distributions using linear combinations of order statistics. J R Stat Society. Series B (Methodological) 52:105-124

Jacob D (2001) A note to the simulation of the annual and interannual variability of the water budget over the Baltic Sea drainage basin. Meteorol Atmos Phys 77:61-73

Jacob D, Van den Hurk BJJM, Andrae U, Elgered G, Fortelius C, Graham LP, Jackson SD, Karstens U, Köpken C, Lindau R, Podzun R, Rockel B, Rubel F, Sass BH, Smith RNB, Yang X (2001) A comprehensive model inter-comparison study investigating the water budget during the BALTEX-PIDCAP period. Meteorol Atmos Phys 77:19-43

Jacob D, Bärring L, Christensen OB, Christensen JH, Castro M, Déqué M, Giorgi F, Hagemann S, Hirschi M, Jones R, Kjellström E, Lenderink G, Rockel B, Sánchez E, Schär C, Seneviratne SI, Somot S, Ulden A, Hurk B (2007) An inter-comparison of regional climate models for Europe: model performance in present-day climate. Clim Change 81:31-52

Jacobeit J (2000) Rezente Klimaentwicklung im Mittelmeerraum. Petermanns Geogr Mitt 144:22-33

Jacobeit J, Dünkeloh A, Hertig E (2007) Mediterranean rainfall changes and their causes. In: Lozan J, Grassl H, Hupfer P, Menzel L, Schönwiese C (eds) Global change: enough water for all? Wissenschaftliche Auswertungen, Hamburg, pp 195-199

Jungclaus JH, Keenlyside N, Botzet M, Haak H, Luo J-J, Latif M, Marotzke J, Mikolajewicz U, Roeckner E (2006) Ocean circulation and tropical variability in the coupled model ECHAM5/MPIOM. J Clim 19:3952-3972

Kharin VV, Zwiers FW (2000) Changes in the extremes in an ensemble of transient climate simulations with a coupled atmosphereOcean GCM. J Clim 13:3760-3788

Kharin VV, Zwiers FW, Zhang X, Wehner M (2013) Changes in temperature and precipitation extremes in the CMIP5 ensemble. Clim Change 119:345-357
Kioutsioukis I, Melas D, Zerefos C (2010) Statistical assessment of changes in climate extremes over Greece (1955-2002). Int J Climatol 30:1723-1737

Kjellström E, Bärring L, Jacob D, Jones R, Lenderink G, Schär C (2007) Modelling daily temperature extremes: recent climate and future changes over Europe. Clim Change 81:249-265

Klein Tank AMG, Können GP (2003) Trends in indices of daily temperature and precipitation extremes in Europe, 1946-99. J Clim $16: 3665-3680$

Klein Tank AMG, Wijngaard JB, Können GP, Böhm R, Demarée G, Gocheva A, Mileta M, Pashiardis S, Hejkrlik L, Kern-Hansen C, Heino R, Bessemoulin P, Müller-Westermeier G, Tzanakou M, Szalai S, Pálsdóttir T, Fitzgerard D, Rubin S, Capaldo M, Maugeri M, Leitass A, Bukantis A, Aberfeld R, Van Engelen AFV, Forland E, Mietus M, Coelho F, Mares C, Razuvaev V, Nieplova E, Cegnar T, Antonio López J, Dahlström B, Moberg A, Kirchhofer W, Ceylan A, Pachaliuk O, Alexander LV, Petrovic P (2002) Daily dataset of the 20th-century surface air temperature and precipitation series for the European climate assessment. Int J Climatol 22:1441-1453

Kostopoulou E, Jones PD (2005) Assessment of climate extremes in the Eastern Mediterranean. Meteorol Atmos Phys 89:69-85

Kuglitsch FG, Toreti A, Xoplaki E, Della-Marta PM, Zerefos CS, Türkes M, Luterbacher J (2010) Heat wave changes in the eastern Mediterranean since 1960. Geophys Res Lett 37:1-5

Kunstmann H, Heckl A, Rimmer A (2006) Physically based distributed hydrological modelling of the upper jordan catchment and investigation of effective model equations. Adv Geosci 9:123-130

Lebel T, Delclaux F, Le Barbe' L, Polcher J (2000) From GCM scales to hydrological scales: rainfall variability in West Africa. Stoch Environ Res Risk Assess 14:275-295

Lionello P, Malanotte-Rizzoli P, Boscolo R, Alpert P, Artale V, Li L, Luterbacher J, May W, Trigo R, Tsimplis M, Ulbrich U, Xoplaki E (2006) The Mediterranean climate: an overview of the main characteristics and issues. In: Lionello P, Malanotte-Rizzoli P, Boscolo $\mathrm{R}$ (eds) Mediterranean climate variability, developments in earth and environmental sciences 4. Elsevier, Amsterdam, pp 1-26

López-Moreno JI, Vicente-Serrano SM, Angulo-Martínez M, Beguería S, Kenawy A (2010) Trends in daily precipitation on the northeastern Iberian Peninsula, 1955-2006. Int J Climatol 30:1026-1041

Luterbacher J, Dietrich D, Xoplaki E, Grosjean M, Wanner H (2004) European seasonal and annual temperature variability, trends, and extremes since 1500. Science 303:1499-1503

Meehl GA, Tebaldi C (2004) More intense, more frequent, and longer lasting heat waves in the 21st century. Science 305:994-997

Miranda PMA, Tomé AR (2009) Spatial structure of the evolution of surface temperature (1951-2004). Clim Change 93:269-284

Moberg A, Jones PD (2005) Trends in indices for extremes in daily temperature and precipitation in central and western Europe, 1901-99. Int J Climatol 25:1149-1171

Moberg A, Jones PD, Lister D, Walther A, Brunet M, Jacobeit J, Alexander LV, Della-Marta PM, Luterbacher J, Yiou P, Chen D, Klein Tank AMG, Saladié O, Sigró J, Aguilar E, Alexandersson H, Almarza C, Auer I, Barriendos M, Begert M, Bergström H, Böhm R, Butler CJ, Caesar J, Drebs A, Founda D, Gerstengarbe F-W, Micela G, Maugeri M, Österle H, Pandzic K, Petrakis M, Srnec L, Tolasz R, Tuomenvirta H, Werner PC, Linderholm H, Philipp A, Wanner H, Xoplaki E (2006) Indices for daily temperature and precipitation extremes in Europe analyzed for the period 19012000. J Geophys Res 111:D22106, 1-25

Nakicenovic N, Swart R (2000) Emissions scenarios. Cambridge University Press, Cambridge

Norrant C, Douguédroit A (2006) Monthly and daily precipitation trends in the Mediterranean (1950-2000). Theor Appl Climatol 83:89-106 
Paeth H, Diederich M (2010) Postprocessing of simulated precipitation for impact research in West Africa. Part II: a weather generator for daily data. Clim Dyn 36:1337-1348

Paeth H, Hense A (2005) Mean versus extreme climate in the Mediterranean region and its sensitivity to future global warming conditions. Meteorol Z 14:329-347

Paeth H, Born K, Podzun R, Jacob D (2005) Regional dynamical downscaling over West Africa: model evaluation and comparison of wet and dry years. Meteorol Z 14:349-367

Paeth H, Born K, Girmes R, Podzun R, Jacob D (2009) Regional climate change in tropical and Northern Africa due to greenhouse forcing and land use changes. J Clim 22:114-132

Pal JS, Giorgi F, Bi X (2004) Consistency of recent European summer precipitation trends and extremes with future regional climate projections. Geophys Res Lett 31:20-23

Palmer TN, Räisänen J (2002) Quantifying the risk of extreme seasonal precipitation events in a changing climate. Nature 415:512-514

Park J-S, Jung H-S, Kim R-S, Oh J-H (2001) Modelling summer extreme rainfall over the Korean peninsula using wakeby distribution. Int J Climatol 21:1371-1384

Pauling A, Luterbacher J, Casty C, Wanner H (2006) Five hundred years of gridded high-resolution precipitation reconstructions over Europe and the connection to large-scale circulation. Clim Dyn 26:387-405

Paxian A, Hertig E, Vogt G, Seubert S, Jacobeit J, Paeth H (2013) Greenhouse gas related predictability of regional climate model trends in the Mediterranean area. Int J Climatol (in review)

Plan Bleu (2005) A sustainable future for the Mediterranean: The blue plan's environment and development Outlook. Earthscan

Plan Bleu and European Investment Bank (EIB) (2008) Climate Change and Energy in the Mediterranean. http://www.planbl eu.org/publications/changement_clim_energie_med_EN.pdf. Accessed 3 February 2011

Rodrigo FS (2010) Changes in the probability of extreme daily precipitation observed from 1951 to 2002 in the Iberian Peninsula. Int J Climatol 30:1512-1525

Roeckner E, Bonaventura L, Brokopf R, Esch M, Giorgetta M, Hagemann S, Kirchner I, Kornblueh L, Manzini E, Rhodin A, Schlese U, Schulzweida U, Tompkins A (2003) The atmospheric general circulation model ECHAM5. PART I: Model description. MPIReport 349. Max-Planck-Institute for Meteorology, Hamburg

Ruti PM, Somot S, Li L, Drobinski P, Elizade A, Giorgi F, Gaertner M, Gallardo C, Carillo A (2010) The MED-CORDEX experiment: underpinning simulations and preliminary validation. Geophys Res Abstr Vol. 12, EGU2010-10008, 2010. EGU General Assembly 2010

Sanchez-Gomez E, Somot S, Mariotti A (2009) Future changes in the Mediterranean water budget projected by an ensemble of regional climate models. Geophys Res Lett 36:1-5

Schönwiese C (2006) Praktische Statistik für Meteorologen und Geowissenschaftler. Borntraeger, Berlin

Semmler T, Jacob D (2004) Modeling extreme precipitation events:a climate change simulation for Europe. Glob Planet Change 44:119-127

Smith R (2003) Chapter 1 Statistics of extremes, with applications in environment, insurance and finance. In: Finkenstadt B, Rootzen $\mathrm{H}$ (eds) Extreme Values in Finance,Telecommunications and the Environment. Chapman and Hall/CRC Press, London, pp 1-78
Sotillo MG, Ratsimandresy AW, Carretero JC, Bentamy A, Valero F, González-Rouco F (2005) A high-resolution 44-year atmospheric hindcast for the Mediterranean Basin: contribution to the regional improvement of global reanalysis. Clim Dyn 25:219-236

Tebaldi C, Hayhoe K, Arblaster JM, Meehl GA (2006) Going to the extremes. Clim Change 79:185-211

Toreti A (2010) Extreme events in the Mediterranean: analysis and dynamics. Dissertation, University of Bern, Switzerland

Toreti A, Xoplaki E, Maraun D, Kuglitsch FG, Wanner H, Luterbacher $\mathrm{J}$ (2010) Characterisation of extreme winter precipitation in Mediterranean coastal sites and associated anomalous atmospheric circulation patterns. Nat Hazards Earth Syst Sci 10:1037-1050

Toreti A, Naveau P, Zampieri M, Schindler A, Scoccimarro E, Xoplaki E, Dijkstra HA, Gualdi S, Luterbacher J (2013) Projections of global changes in precipitation extremes from coupled model intercomparison project Phase 5 models. Geophys Res Lett 40:4887-4892

Trigo RM, Pereira JMC, Pereira MG, Mota B, Calado TJ, Dacamara CC, Santo FE (2006) Atmospheric conditions associated with the exceptional fire season of 2003 in Portugal. Int J Climatol 26:1741-1757

Turato B, Reale O, Siccardi F (2004) Water vapor sources of the october 2000 piedmont flood. J Hydrometeorol 5:693-712

Uppala SM, Kallberg PW, Simmons AJ, Andrae U, Bechtold VDC, Fiorino M, Gibson JK, Haseler J, Hernandez A, Kelly GA, Li X, Onogi K, Saarinen S, Sokka N, Allan RP, Andersson E, Arpe K, Balmaseda MA, Beljaars ACM, Van de Berg L, Bidlot J, Bormann N, Caires S, Chevallier F, Dethof A, Dragosavac M, Fisher M, Fuentes M, Hagemann S, Hólm E, Hoskins BJ, Isaksen L, Janssen PAEM, Jenne R, Mcnally AP, Mahfouf J-F, Morcrette J-J, Rayner NA, Saunders RW, Simon P, Sterl A, Trenberth KE, Untch A, Vasiljevic D, Viterbo P, Woollen J (2005) The ERA-40 re-analysis. Q J R Meteorol Soc 131:2961-3012

Von Storch H, Zwiers F (1999) Statistical analysis in climate research. Cambridge University Press, Cambridge

Voss R, May W, Roeckner E (2002) Enhanced resolution modelling study on anthropogenic climate change: changes in extremes of the hydrological cycle. Int J Climatol 22:755-777

Vrac M, Naveau P (2007) Stochastic downscaling of precipitation: from dry events to heavy rainfalls. Water Resour Res 43:1-13

Wijngaard JB, Klein Tank AMG, Koennen GP (2003) Homogeneity of 20th century European daily temperature and precipitation series. Int J Climatol 23:679-692

Wilks D (1999) Multisite downscaling of daily precipitation with a stochastic weather generator. Clim Res 11:125-136

Wilks DS (2006) Statistical methods in the atmospheric sciences, 2nd edn. Elsevier Academic Press, Amsterdam

Xoplaki E (2002) Climate variability over the Mediterranean. Dissertation, University of Bern, Switzerland

Xoplaki E, Gonzalez-Rouco J, Luterbacher J, Wanner H (2004) Wet season Mediterranean precipitation variability: influence of largescale dynamics and trends. Clim Dyn 23:63-78

Zhang X, Hegerl G, Zwiers FW, Kenyon J (2005) Avoiding inhomogeneity in percentile-based indices of temperature extremes. $\mathrm{J}$ Clim 18:1641-1651

Zolina O, Kapala A, Simmer C, Gulev S (2004) Analysis of extreme precipitation over Europe from different reanalyses: a comparative assessment. Glob Planet Change 44:129-161 